\title{
Breastfeeding Shows a Protective Trend toward Adolescents with Higher Abdominal Adiposity
}

\author{
Julien Rousseaux ${ }^{a} \quad$ Alain Duhamel ${ }^{a}$ Dominique Turck ${ }^{b}$ Denes Molnar ${ }^{c}$ \\ Julia Salleron $^{a}$ Enrique Garcia Artero ${ }^{d}$ Stefaan De Henauw ${ }^{\mathrm{e}}$ \\ Sabine Dietrich $^{f}$ Yannis Manios $^{g}$ Raffaela Piccinelli ${ }^{\text {h }}$ Michael Sjöström $^{i}$ \\ Luis Aznar Moreno ${ }^{j} \quad$ Frédéric Gottrand ${ }^{b}$ \\ aUnité de Biostatistiques, CERIM, EA2694, UDSL, Université Lille Nord de France, Lille, \\ France; 'b Inserm U995, IFR114, Department of Pediatrics, Faculty of Medicine, University \\ Lille 2, Lille, France; ' ${ }^{\mathrm{D}}$ Department of Pediatrics, University of Pécs, Pécs, Hungary; \\ ${ }^{d}$ Department of Physical Education and Sport, School of Education, University of Almeria, \\ Almeria, Spain; ' Department of Public Health, Faculty of Medicine and Health Sciences, \\ Ghent University, Ghent, Belgium; ${ }^{f}$ Klinische Psychologie, Gesundheitspsychologie \\ Psychosomatisches Zentrum Waldviertel, Eggenburg, Austria; 9 Department of Nutrition \\ and Dietetics, Harokopio University, Athens, Greece; ${ }^{h}$ Research Institute on Food and \\ Nutrition, Rome, Italy; 'Unit for Preventive Nutrition, Department of Biosciences and \\ Nutrition, Karolinska Institute, Huddinge, Sweden; ${ }^{j}$ GENUD (Growth, Exercise, Nutrition and \\ Development) Research Group, Escuela Universitaria de Ciencias de la Salud, Universidad \\ de Zaragoza, Zaragoza, Spain
}

\section{Key Words}

Breastfeeding · Body composition · Adolescents · Waist-to-height ratio · BMI · Propensity score

\section{Abstract}

Objective: The question of whether breastfeeding has a protective effect against the development of overweight or obesity later in life remains controversial, especially during adolescence. The objective was to assess the relationship between breastfeeding and adolescents' body composition. Methods: The HELENA study is a cross-sectional study involving 3,528 adolescents from 10 European cities. The outcome measures were body weight and height, subscapular skinfolds as well as waist circumferences. Breastfeeding, smoking status, and parental socioeconomic status were assessed by self-administered questionnaires. Dietary intake was recorded using two 24-hour recall surveys. Two adjustment approaches were used: i) covariance analysis adjusted for confounding factors (propensity score adjustment) and ii) multivariate quantile regression. Results: After adjustment, no significant associations were 
Rousseaux et al.: Breastfeeding Shows a Protective Trend toward Adolescents with Higher Abdominal Adiposity

observed between breastfeeding and body composition parameters (BMI Z-score; sum of skinfolds; waist-to-height ratio). An adjusted quantile regression analysis showed a non-significant trend for a protective effect of breastfeeding toward the highest percentiles of adiposity in boys but not in girls. This is of particular interest with respect to the superiority of the waist-to-height ratio over waist circumference and BMI for detecting cardiometabolic risk factors. Conclusion: This first European study, including a large set of factors influencing adolescents' body composition, showed a non-significant trend toward a protective effect of breastfeeding on highest percentiles of adolescent's abdominal adiposity.

(C) 2014 S. Karger GmbH, Freiburg

\section{Introduction}

Breastfeeding is the recommended mode of infant feeding [1] and has several advantages compared with formula feeding, the most of which important is a lower risk of infectious diseases. Breastfeeding is also thought to be associated with a lower risk of developing obesity in childhood and adolescence. This last point is still a matter of debate [2-4].

Breastfeeding was first suggested to influence body composition in 1980 by Marmot et al. [5]. Since then, several meta-analyses have been published on this topic [6-8]. The last two published meta-analyses have shown a beneficial effect of breastfeeding on body composition, The first one was limited to children aged less than 1 year [9], and the other one, conducted for the World Health Organization (WHO) without age limitation, found a protective effect of breastfeeding but results were attenuated by a clear evidence of publication biases [2].

Adolescence is a key period for nutritional issues. It has been shown that the likelihood of becoming obese as an adult is greater for obese adolescents; the odds ratio of being obese in adulthood is 16 for the highest BMI [10]. BMI is the most common way to assess body composition in clinical practice and in many studies, but is only an estimate of adiposity. The relationship between breastfeeding and body composition should be explored with better accuracy by analyzing subcutaneous and abdominal adiposity $[11,12]$.

Our analysis is based on the Healthy Lifestyle in Europe by Nutrition in Adolescence (HELENA) study. This is a European multicenter and cross-sectional study that aims to investigate the nutritional status and lifestyle of European adolescents [13]. 3,910 adolescents were recruited for anthropometric measurements and questionnaires about their way of life. Collected data for analysis of the effect of breastfeeding on body composition included data about breastfeeding as well as many confounding factors to take in consideration.

As previous publications were discordant, due to power weakness and/or to adjustment inadequacy, the objective of the present study was to assess the relationship between breastfeeding and adiposity in a large population of adolescents taking into account a large set of confounding factors.

\section{Material and Methods}

Design

Data derived from the HELENA-Cross Sectional Study (CSS), a multicenter study aiming to obtain reliable and comparable data on nutrition and health-related parameters. A total of 3,528 adolescents (age range 12.5-17.5 years) were assessed at school between 2006 and 2007 in 10 European cities from 9 countries, all fulfilling the general HELENA-CSS inclusion criteria [13]. Details on sampling procedures and study design have been reported elsewhere [14]. The ethical committee of each clinic involved approved the study [15]. Written informed consent was obtained from both adolescents and their parents. 
Rousseaux et al.: Breastfeeding Shows a Protective Trend toward Adolescents with

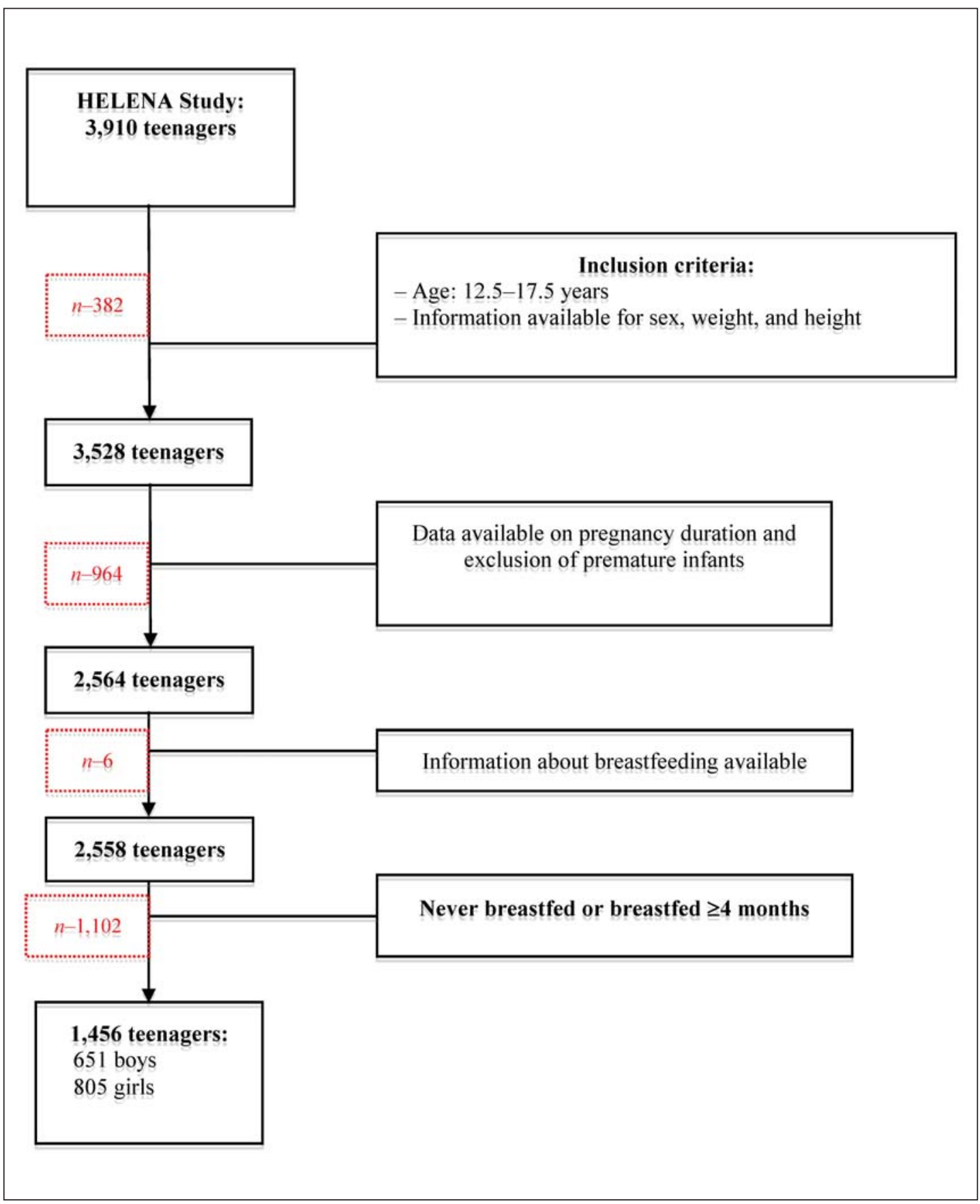

Fig. 1. Selection of the population studied.

Information about breastfeeding was available for 2,848 adolescents from a specific parental questionnaire. In our analysis, we included adolescents who were not born prematurely ( $<35$ weeks gestation), for whom we had data on pregnancy duration $(n=2,564)$, and who were either never breastfed $(n=440)$ or breastfed for $\geq 4$ months ( $n=1,016$ ) (fig. 1). In order to raise the capability to assess the role of breastfeeding we excluded subjects who were breastfed for less than 4 months as this is a heterogeneous category including very short times of breastfeeding. The group excluded is not different considering sex ratio, age, or socioeconomic status (SES). 
Rousseaux et al.: Breastfeeding Shows a Protective Trend toward Adolescents with Higher Abdominal Adiposity

\section{Anthropometric Data}

The following anthropometric parameters were measured: i) Height (Seca225; precision $1 \mathrm{~mm}$; Seca GmbH \& Co, Hamburg, Germany) and weight (electronic scale: Seca861; precision 0.05 kg; Seca GmbH \& Co); ii) skinfolds: biceps, triceps, subscapular, suprailiac, calf, and hip (in triplicate on the left side of the body using Holtain calipers; precision $0.2 \mathrm{~mm}$; Holtain Ltd., Crymych, UK); and iii) waist circumference (in triplicate with a nonelastic tape; Seca200, precision $0.1 \mathrm{~cm}$; Seca GmbH \& Co). These measures were obtained under standardized conditions [16]. BMI and waist-to height ratio were calculated. Sexual maturation was assessed by a medical doctor using the method of Tanner and Whitehouse [17].

\section{SES}

The SES of the adolescents was assessed using the Family Affluence Scale (FAS III) [18]. The FAS III records items, such as 'having his/her own bedroom', 'number of cars' and 'number of computers', and produces a score from 0 to 6 points where 0 is the lowest grade and 6 is the highest. The SES was also evaluated according to the parents' educational level as elementary school / high school / college degree / engineering or university degree; subjective family affluence (very well off, quite well off, average well off, not very well off, not very well off at all) [19]; and the International Standard Classification of Occupations (ISCO) category of the father's occupation, which was classified into one of four categories. The evaluation of SES has been described in detail previously [19].

\section{Neonatal Information}

Characteristics of breastfeeding and its duration were collected from parents using a specific questionnaire. All countries participating in the HELENA study used a health booklet that referred to the type of infant feeding and its duration. The other neonatal data collected were weight, length at birth, and gestational age.

\section{Physical Fitness}

Several physical fitness parameters were measured: cardiorespiratory fitness (20 m shuttle run); muscular speed, agility, and coordination (4 410 m shuttle run); muscular strength (hand grip); lower limb explosive strength and coordination (squat jump, Abalakov jump, countermovement jump); flexibility (back saver sit and reach); and explosive strength (standing broad jump). These tests have been described in detail previously [20].

\section{Nutritional Intake}

The instrument Young Adolescents' Nutrition Assessment on Computer [21] was adapted for the HELENA study and called HELENA-DIAT [22]. It is a 24-hour recall assessment tool based on six meal occasions referring to the day before the interview. The validity of the instrument has been investigated against food records and interviews, and is described in detail elsewhere [21]. The data were cross-checked with the German BLS database [23] to extract energy and nutrient intake. Underreporters were identified with the Goldberg method [24]. All mean intakes for the 2 nonconsecutive days were calculated by applying the multiple source method using two different strategies: including the underreporters versus excluding the underreporters. For our analysis, we included energy consumed per day (kcal/day) and fat consumed per day (g/day).

\section{Reliability}

All measurements followed written detailed operating procedures translated into the local language to ensure that the same verbal information was given to all participants in the HELENA study.

Two workshops were conducted in which all field workers in charge of measurements were trained in the methods to obtain the anthropometric measurements in each of the 10 centers. A pilot study involving 202 adolescents from the 10 centers was also performed to check for inaccuracy and to adapt the procedure and questionnaires before the study began. Socioeconomic and parental questionnaire items that caused problems or raised questions as well as those completed by $<85 \%$ of the adolescents were reviewed for deletion or modification $[19,25]$.

Because anthropometric and fitness measurements are sensitive to interobserver variability, reliability was tested $[25,26]$. For skinfolds and circumference, the interobserver reliability was tested and was always $>90 \%$. The reliability of physical fitness tests was acceptable; no learning or fatigue effects were found for any of the physical fitness tests when repeated. 
Rousseaux et al.: Breastfeeding Shows a Protective Trend toward Adolescents with Higher Abdominal Adiposity

\section{Ethical Considerations}

This study was conducted according to the guidelines laid down in the Declaration of Helsinki in its revised version, and all procedures involving human subjects were approved by the ethics committee in each participating country. Written informed consent was obtained from all subjects and their parents [15].

\section{Variable Selection}

Several body composition variables were selected a priori: BMI Z-score (following the Cole calculation [27]), sum of six skinfolds (log-transformed) to investigate subcutaneous adiposity (biceps, triceps, subscapular, suprailiac, thigh, calf), and waist-to-height ratio to explore abdominal adiposity [28-31].

Confounders that could influence body composition were selected: adolescents' smoking habit (dichotomized as $\leq 10$ cigarettes/week and >10 cigarettes/week), age, all fitness data as continuous variables, sedentary lifestyle (time spent watching TV and playing videogames during school days and sleep duration on weeknights), mother's and father's body composition (assessed as obese/overweight, normal, underweight according to adolescents' perception), study center, puberty (Tanner staging), SES, parental educational level (elementary school / high school / college degree / engineering or university degree), energy, and fat intake.

\section{Statistical Analysis}

Numeric variables are expressed as mean and standard deviation (SD), and qualitative variables as frequency and percentage. Because the distribution of the sum of six skinfolds was skewed, all analyzes involving the sum of six skinfolds were performed after log-transformation (natural logarithm). Continuous and qualitative variables were analyzed by Student's t test or $\chi^{2}$ test, respectively.

Body composition variables were studied for the whole population and then for boys and girls separately.

Each body composition variable (BMI Z-score, waist-to-height ratio, log-transformation of the sum of skinfolds) was examined as follows. The potential confounding variables were analyzed successively by bivariate analysis. The binary and nominal variables were tested with Student's t test and analysis of variance (ANOVA), respectively. Continuous and ordinal variables were tested with Pearson's and Spearman's correlation, respectively.

The adjustment for confounders was performed using the propensity score method. This method is a two-step procedure. In the first step, logistic regression was performed with breastfeeding as the dependent variable and the confounders as independent variables. In the second step, the effect of breastfeeding on each body composition parameter was adjusted for the propensity score using covariance analysis. The selected confounders were related both with breastfeeding and with the outcome [32]; propensity score method provides better results than multivariable linear regression for adjustment on confounders (it is less concerned by the problem of overadjustment). Co-linearity was pursued with exclusion of each variable with variance inflation factor $\geq 3$. Finally, a quantile regression [33] was performed to integrate the propensity score to adjust for confounding factors related to breastfeeding.

Data were analyzed using Statistical Analysis Systems statistical software, version 9.1 (SAS Institute, Cary, NC, USA). $\mathrm{p}<0.05$ was considered significant.

\section{Results}

The mean age of participating adolescents was $14.7 \pm 1.2$ years and was the same in each sex group (males $14.7 \pm 1.2$, females $14.7 \pm 1.2$ years). Compared with adolescents who were never breastfed (table 1), the breastfed group had lower BMI for the whole group and for boys but not for girls. The same pattern was observed for the sum of skinfolds and the waist-toheight ratio.

The bivariate analysis between the outcomes and confounding factors identified factors with a significance level $<0.2$ that were introduced in the propensity score for the adjusted analysis (table 2). 
Table 1. Effect of breastfeeding on body composition variables in the bivariate analysis

\begin{tabular}{|c|c|c|c|c|c|c|c|c|c|c|c|c|c|c|c|}
\hline \multirow{3}{*}{$\begin{array}{l}\text { Relationship } \\
\text { with } \\
\text { breastfeeding } \\
\text { (never vs. } \geq 4 \\
\text { months) }\end{array}$} & \multicolumn{4}{|c|}{ Boys $(\mathrm{n}=651)$} & \multirow{3}{*}{$\begin{array}{l}\mathrm{p} \\
\text { Value }\end{array}$} & \multicolumn{4}{|c|}{ Girls $(n=805)$} & \multirow{3}{*}{$\begin{array}{l}\mathrm{p} \\
\text { Value }\end{array}$} & \multicolumn{4}{|c|}{ Total population $(\mathrm{n}=1,456)$} & \multirow{3}{*}{$\begin{array}{l}\mathrm{p} \\
\text { Value }\end{array}$} \\
\hline & \multicolumn{2}{|c|}{ breastfed } & \multicolumn{2}{|c|}{ not breastfed } & & \multicolumn{2}{|c|}{ breastfed } & \multicolumn{2}{|c|}{ not breastfed } & & \multicolumn{2}{|c|}{ breastfed } & \multicolumn{2}{|c|}{ not breastfed } & \\
\hline & mean & SD & mean & SD & & mean & SD & mean & SD & & mean & SD & mean & SD & \\
\hline BMI Z score & 0.48 & 1.11 & 0.70 & 1.21 & 0.027 & 0.32 & 1.07 & 0.41 & 1.19 & 0.32 & 0.4 & 1.04 & 0.53 & 1.20 & 0.04 \\
\hline Skinfolds & 4.13 & 0.44 & 4.24 & 0.45 & 0.04 & 4.5549 & 0.34 & 4.58 & 0.36 & 0.44 & 4.38 & 0.43 & 4.46 & 0.43 & 0.001 \\
\hline WHR & 0.43 & 0.05 & 0.45 & 0.06 & 0.001 & 0.4312 & 0.05 & 0.44 & 0.05 & 0.13 & 0.43 & 0.05 & 0.44 & 0.05 & $<0.001$ \\
\hline
\end{tabular}

Table 2. Significance of bivariate associations with body composition

\begin{tabular}{|c|c|c|c|c|c|c|c|c|c|}
\hline & \multicolumn{3}{|c|}{ BMI-Z score ( $\mathrm{p}$ value) } & \multicolumn{3}{|c|}{ Sum of six skinfolds (p value) } & \multicolumn{3}{|c|}{ Waist-to-height ratio ( $\mathrm{p}$ value) } \\
\hline & boys & girls & total & boys & girls & total & boys & girls & total \\
\hline Smoking & $0.8^{*}$ & $0.01^{*}$ & $0.1^{*}$ & $0.04^{*}$ & $0.24^{*}$ & $0.38^{*}$ & $0.66^{*}$ & $0.07^{*}$ & $0.01^{*}$ \\
\hline Sex & - & - & $<0.001^{*}$ & - & - & $<0.001^{*}$ & - & - & $0.08^{*}$ \\
\hline Center & $<0.001^{* *}$ & $<0.001^{* *}$ & $<0.001^{* *}$ & $<0.001^{* *}$ & $<0.001^{* *}$ & $<0.001^{* *}$ & $<0.001^{* *}$ & $<0.001^{* *}$ & $<0.001^{* *}$ \\
\hline ISCO (father) & $0.27^{* *}$ & $<0.001^{* *}$ & $<0.001^{* *}$ & $0.11^{* *}$ & $0.001^{* *}$ & $<0.001^{* *}$ & $0.03^{* *}$ & $<0.001^{* *}$ & $<0.001^{* *}$ \\
\hline Pubertal status & $0.002^{\#}$ & $<0.001^{\#}$ & $<0.001^{\#}$ & $0.02^{\#}$ & $<0.001^{\#}$ & $<0.001^{\#}$ & $0.59^{\#}$ & $<0.001^{\#}$ & $<0.001^{\#}$ \\
\hline Mother's weight & $0.02^{\#}$ & $<0.001^{\#}$ & $<0.001^{\#}$ & $0.42^{\#}$ & $<0.001^{\#}$ & $<0.001^{\#}$ & $0.02^{\#}$ & $<0.001^{\#}$ & $<0.001^{\#}$ \\
\hline Father's weight & $0.02^{\#}$ & $0.006^{\#}$ & $<0.001^{\#}$ & $0.28^{\#}$ & $0.31^{\#}$ & $0.11^{\#}$ & $0.06^{\#}$ & $0.04^{\#}$ & $0.005^{\#}$ \\
\hline Perceived affluence & $0.68^{\#}$ & $0.98^{\#}$ & $0.95^{\#}$ & $0.35^{\#}$ & $0.36^{\#}$ & $0.29^{\#}$ & $0.62^{\#}$ & $0.24^{\#}$ & $0.22^{\#}$ \\
\hline Mother's educational level & $0.003^{\#}$ & $<0.001^{\#}$ & $<0.001^{\#}$ & $0.08^{\#}$ & $0.002^{\#}$ & $<0.001^{\#}$ & $<0.001^{\#}$ & $<0.001^{\#}$ & $<0.001^{\#}$ \\
\hline Father's educational level & $0.01^{\#}$ & $<0.001^{\#}$ & $<0.001^{\#}$ & $0.12^{\#}$ & $<0.001^{\#}$ & $<0.001^{\#}$ & $<0.001^{\#}$ & $<0.001^{\#}$ & $<0.001^{\#}$ \\
\hline FAS III & $0.001^{\#}$ & $<0.001^{\#}$ & $<0.001^{\#}$ & $0.01^{\#}$ & $<0.001^{\#}$ & $<0.001^{\#}$ & $0.002^{\#}$ & $0.002^{\#}$ & $<0.001^{\#}$ \\
\hline TV duration & $0.002^{\#}$ & $0.01^{\#}$ & $<0.001^{\#}$ & $0.004^{\#}$ & $<0.001^{\#}$ & $<0.001^{\#}$ & $0.004^{\#}$ & $<0.001^{\#}$ & $<0.001^{\#}$ \\
\hline Video game duration & $<0.001^{\#}$ & $0.05^{\#}$ & $<0.001^{\#}$ & $<0.001^{\#}$ & $0.85^{\#}$ & $<0.001^{\#}$ & $<0.001^{\#}$ & $0.05^{\#}$ & $<0.001^{\#}$ \\
\hline Age & $0.06^{\# \#}$ & $0.04^{\# \#}$ & $0.006^{\# \#}$ & $<0.001^{\# \#}$ & $<0.001^{\# \#}$ & $0.1^{\# \#}$ & $0.05^{\# \#}$ & $0.01^{\# \#}$ & $0.77^{\# \#}$ \\
\hline Birth weight & $0.14^{\# \#}$ & $0.06^{\# \#}$ & $0.003^{\# \#}$ & $0.31^{\# \#}$ & $0.2^{\# \#}$ & $0.36^{\# \#}$ & $0.99^{\# \#}$ & $0.27^{\# \#}$ & $0.59^{\# \#}$ \\
\hline Birth length & $0.06^{\# \#}$ & $0.07^{\# \#}$ & $0.001^{\# \#}$ & $0.12^{\# \#}$ & 1. & $0.09^{\# \#}$ & $0.52^{\# \#}$ & $0.2^{\# \#}$ & $0.25^{\# \#}$ \\
\hline Sleep duration & $0.98^{\# \#}$ & $0.01^{\# \#}$ & $0.12^{\# \#}$ & $0.03^{\# \#}$ & $0.01^{\# \#}$ & $0.34^{\# \#}$ & $0.01^{\# \#}$ & $0.05^{\# \#}$ & $0.58^{\# \#}$ \\
\hline Standing broad jump & $<0.001^{\# \#}$ & $<0.001^{\# \#}$ & $<0.001^{\# \#}$ & $<0.001^{\# \#}$ & $<0.001^{\# \#}$ & $<0.001^{\# \#}$ & $<0.001^{\# \#}$ & $<0.001^{\# \#}$ & $<0.001^{\# \#}$ \\
\hline $4 \times 10 \mathrm{~m}$ shuttle run & $<0.001^{\# \#}$ & $<0.001^{\# \#}$ & $<0.001^{\# \#}$ & $<0.001^{\# \#}$ & $<0.001^{\# \#}$ & $<0.001^{\# \#}$ & $<0.001^{\# \#}$ & $<0.001^{\# \#}$ & $<0.001^{\# \#}$ \\
\hline 20 m shuttle run & $<0.001^{\# \#}$ & $<0.001^{\# \#}$ & $<0.001^{\# \#}$ & $<0.001^{\# \#}$ & $<0.001^{\# \#}$ & $<0.001^{\# \#}$ & $<0.001^{\# \#}$ & $<0.001^{\# \#}$ & $<0.001^{\# \#}$ \\
\hline Squat jump & $<0.001^{\# \#}$ & $<0.001^{\# \#}$ & $<0.001^{\# \#}$ & $<0.001^{\# \#}$ & $<0.001^{\# \#}$ & $<0.001^{\# \#}$ & $<0.001^{\# \#}$ & $<0.001^{\# \#}$ & $<0.001^{\# \#}$ \\
\hline Countermovement jump & $<0.001^{\# \#}$ & $<0.001^{\# \#}$ & $<0.001^{\# \#}$ & $<0.001^{\# \#}$ & $<0.001^{\# \#}$ & $<0.001^{\# \#}$ & $<0.001^{\# \#}$ & $<0.001^{\# \#}$ & $<0.001^{\# \#}$ \\
\hline Abalakov jump & $<0.001^{\# \#}$ & $<0.001^{\# \#}$ & $<0.001^{\# \#}$ & $<0.001^{\# \#}$ & $<0.001^{\# \#}$ & $<0.001^{\# \#}$ & $<0.001^{\# \#}$ & $<0.001^{\# \#}$ & $<0.001^{\# \#}$ \\
\hline Hand grip & $<0.001^{\# \#}$ & $<0.001^{\# \#}$ & $<0.001^{\# \#}$ & $0.14^{\# \#}$ & $0.004^{\# \#}$ & $<0.001^{\# \#}$ & $0.61^{\# \#}$ & $0.002^{\# \#}$ & $0.008^{\# \#}$ \\
\hline Back-saver sit and reach & $0.001^{\# \#}$ & $0.91^{\# \#}$ & $0.87^{\# \#}$ & $0.33^{\# \#}$ & $0.003^{\# \#}$ & $<0.001^{\# \#}$ & $0.84^{\# \#}$ & $0.08^{\# \#}$ & $0.1^{\# \#}$ \\
\hline Energy consumption (kcal/day) & $0.07^{\# \#}$ & $<0.001^{\# \#}$ & $0.02^{\# \#}$ & $<0.001^{\# \#}$ & $<0.001^{\# \#}$ & $<0.001^{\# \#}$ & $0.013^{\# \#}$ & $<0.001^{\# \#}$ & $<0.001^{\# \#}$ \\
\hline Fat consumption (g/day) & $0.24^{\# \#}$ & $<0.001^{\# \#}$ & $0.04^{\# \#}$ & $<0.001^{\# \#}$ & $<0.001^{\# \#}$ & $<0.001^{\# \#}$ & $0.05^{\# \#}$ & $0.005^{\# \#}$ & $0.002^{\# \#}$ \\
\hline
\end{tabular}

ISCO = International Standard Classification of Occupations; FAS = Family Affluence Scale.

*Student's t test; **ANOVA; \# Spearman correlation; \#\#Pearson correlation.

Multivariate analysis using the propensity score did not show any significant associations between breastfeeding and BMI, fat free mass index (FFMI), skinfold thickness, or waistto-height ratio (table 3). Multivariate analyzes by sex did not show any significant association.

Quantile regression provided results by percentiles for each outcome. The quantile regression for whole population showed that breastfeeding was not significantly associated with BMI, FFMI, skinfold thickness, or waist-to-height ratio, except for the 90th percentile of waist-to-height ratio in the total population (data not shown). 
Rousseaux et al.: Breastfeeding Shows a Protective Trend toward Adolescents with Higher Abdominal Adiposity

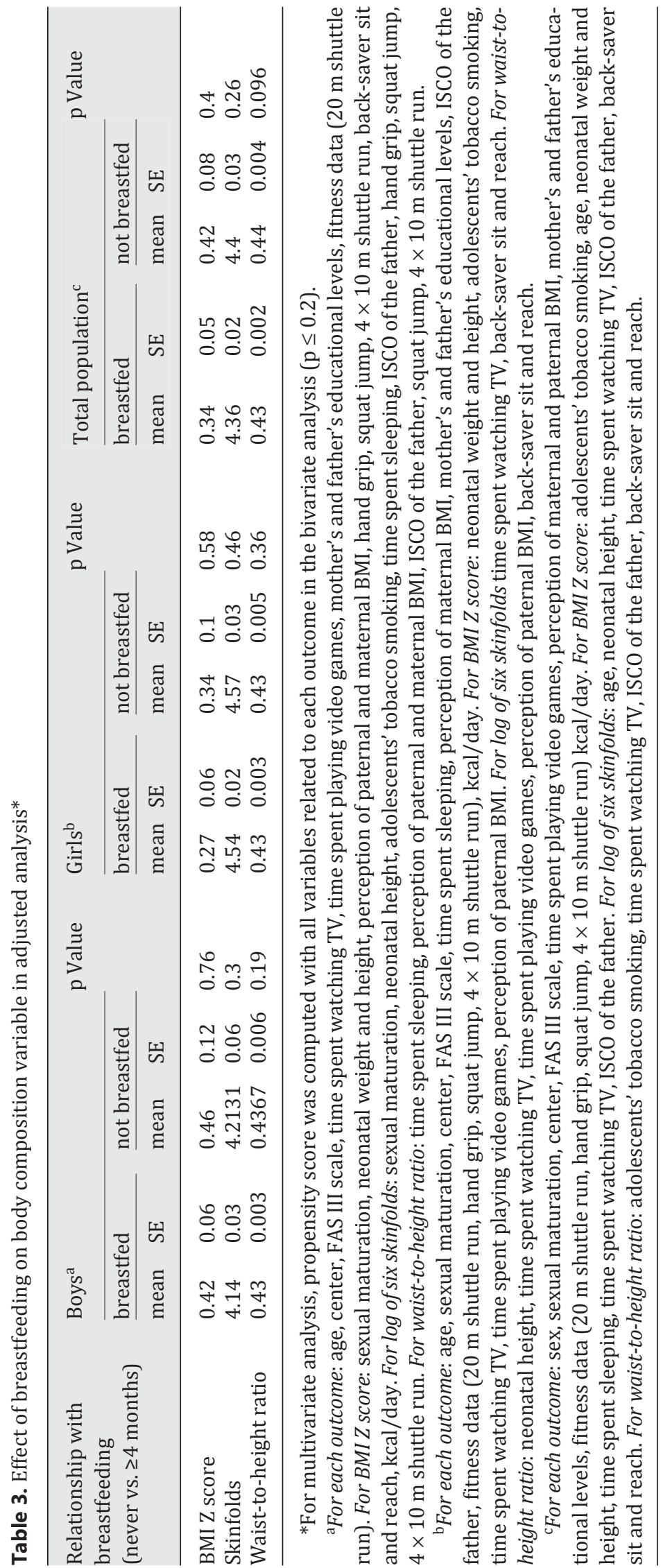


Rousseaux et al.: Breastfeeding Shows a Protective Trend toward Adolescents with Higher Abdominal Adiposity
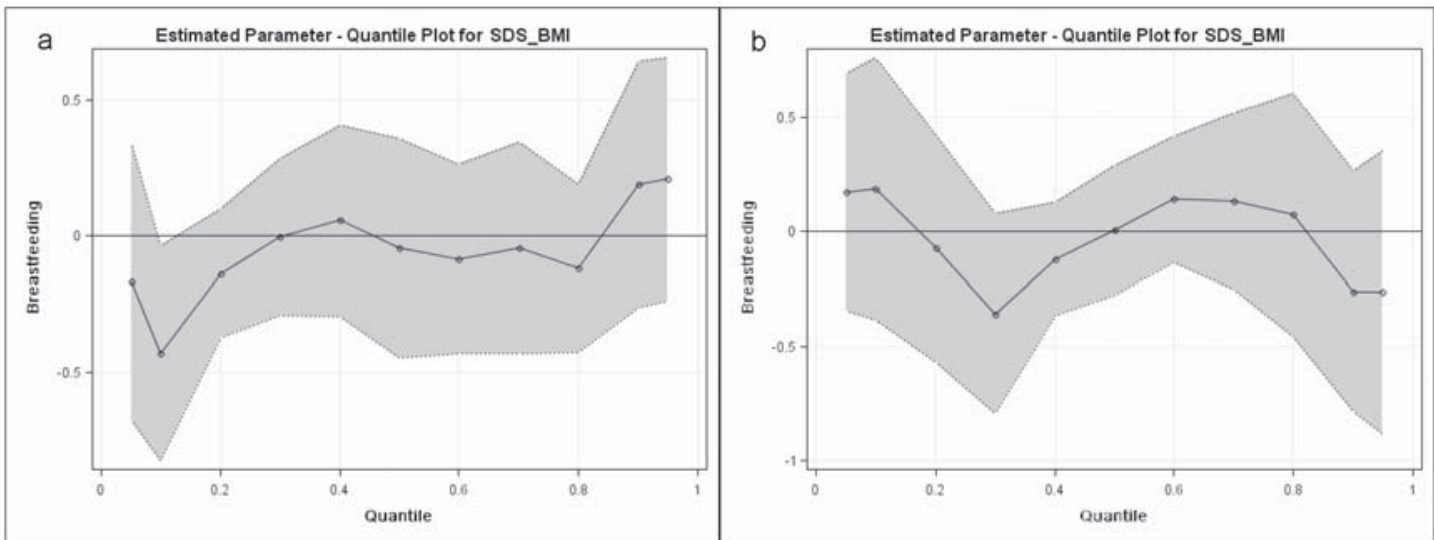

Fig. 2. Quantile repartition of BMI Z score (SDS-BMI). a Girls, b boys.

The black points represent the adjusted protective effect of breastfeeding following the values of BMI Z score. A point below zero means that breastfeeding has a lowering effect on the considered BMI Z score. The grey zone represents the confidence interval.

Same adjustment as in table 3.

SDS-BMI = Standard deviation score for BMI.
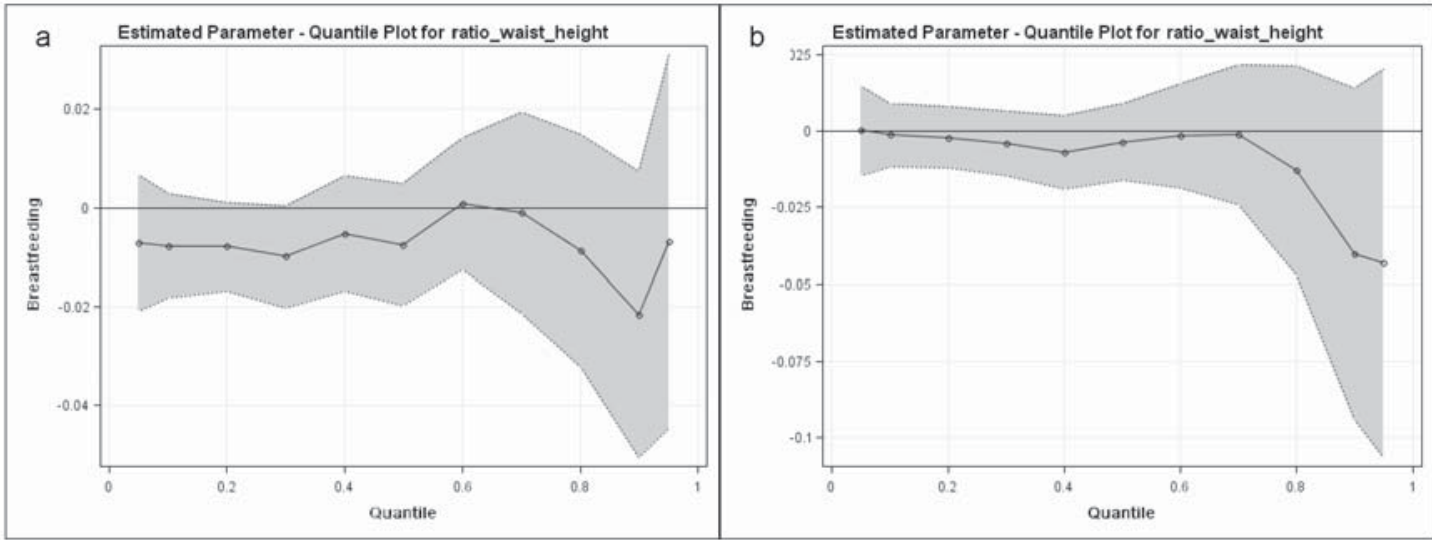

Fig. 3. Quantile repartition of waist-to-height ratio. a Girls, b boys.

The black points represent the adjusted protective effect of breastfeeding following the values of waist-toheight ratio. A point below zero means that breastfeeding has a lowering effect on the considered waist-toheight ratio. The grey zone represents the confidence interval.

Same adjustment as in table 3.

The analysis was performed separately for girls and boys (fig. 2-4). In girls, breastfeeding was not associated with any of the outcomes. In boys, quantile regression analysis showed a non-significant tendency toward a protective effect of breastfeeding on the highest percentiles of skinfolds and waist-to-height ratio. BMI did not correlate with breastfeeding in any percentile. 
Rousseaux et al:: Breastfeeding Shows a Protective Trend toward Adolescents with Higher Abdominal Adiposity
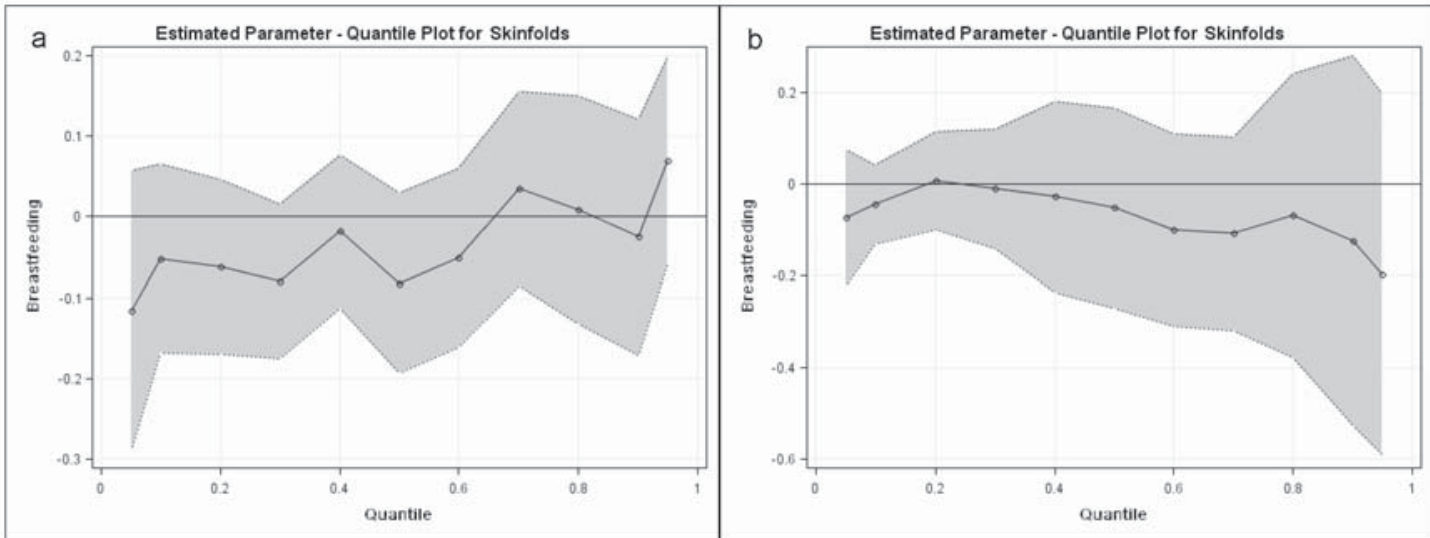

Fig. 4. Quantile repartition of sum of skinfolds. a Girls, b boys.

The black points represent the adjusted protective effect of breastfeeding following the values of sum of skinfolds. A point below zero means that breastfeeding has a lowering effect on the considered sum of skinfolds. The grey zone represents the confidence interval.

Same adjustment as in table 3.

\section{Discussion}

Our study confirms that, when confounders such as sociocultural factors, physical fitness and dietary data (daily fat, energy consumption) are taken into account, no effect of breastfeeding on adiposity can be observed in the whole population of adolescents. The new finding of our study is that quantile regression analysis suggests a protective effect of breastfeeding on the highest percentiles of abdominal adiposity and subcutaneous fatness. This might be of clinical interest because people with higher visceral fat are the most likely to develop cardiovascular diseases later in life [34].

Five studies have investigated the relationship between breastfeeding and body composition in adolescence [35-39], but there are some discrepancies between their results. Two studies concluded to a relationship: The first study showed a beneficial association between breastfeeding and BMI and skinfolds in girls. However, the authors did not adjust for confounding factors [35]. In 2012, Yin et al. [39] reported a negative association between breastfeeding and adolescents' fat mass. Three other studies did not find any influence of breastfeeding [36-38].

All together these studies and our results suggest that, when taking into account confounders, there is no protective effect of breastfeeding on fatness in adolescents. To avoid the risk of underestimation of the effect when taking into account multiple confounders, we used the propensity score. Indeed the propensity score is a tool allowing to compare two groups when counfounders are numerous and randomization is impossible [40], as is the case for breastfeeding, thus strengthens the conclusion. This is the first time that such method is used to assess precisely the relationship between breastfeeding and adiposity in adolescents.

The composition of infant formula is different from breast milk, not only for the amount of protein but also for the amino acid composition. These differences in protein content in infant milk lead to higher dosage of insulin-like growth factor 1 in 12-month-old children [41]. This 'early protein hypothesis' could track until the age of 6 years, as recently demonstrated by Koletzko et al. [42] in a randomized study that showed higher mean BMI in children who were fed higher protein formula for the first year of life. However, whether or not such difference persists until adolescence remains to be assessed. 
Rousseaux et al.: Breastfeeding Shows a Protective Trend toward Adolescents with Higher Abdominal Adiposity

It was suggested recently that the beneficial effect of breastfeeding might act by reducing the prevalence of overweight, obesity, and underweight [43]; quantile regression analysis is required to further investigate possible breastfeeding effects. The quantile regression analysis did not identify any effect of breastfeeding on the BMI Z-score, regardless of the percentile studied. However, our results apply only to a healthy population and cannot be generalized to an obese population. One interesting finding of this study is that it suggests that breastfeeding has a protective effect in the highest percentiles of abdominal fatness. We choose to analyze the waist-to-height ratio owing to its superiority on waist circumference and BMI for detecting cardiometabolic risk factors [44], but also for detecting all-cause mortality [45].

Our study has strengths but also limitations. It included a large cohort of well-phenotyped adolescents, with a very large set of data that included most of the factors known to influence body composition such as physical fitness, physical activity, environmental factors, SES, and food intake. Our study used a high standard of methodology and involved a large population of adolescents within Europe, and it is likely that its results can be generalized to industrialized countries.

The lack of a finding of beneficial effects of breastfeeding on body composition raises the question of a lack of statistical power. We performed a posteriori power calculations based on BMI. Considering an $\alpha$ risk of $5 \%$ and given the number of subjects included, our study had a power of $95 \%$ to detect a 0.2 effect size, meaning that our sample should identify a significant BMI difference of 0.7 between the breastfed and non-breastfed groups (observed SD 3.7).

Our study has also weaknesses. Parental body composition was estimated by the adolescents because the investigators could not obtain these measurements from the parents. Our study used a cross-sectional design, which does not allow the demonstration of a causal relationship. Another limitation of the study is the retrospective assessment of breastfeeding. Several articles have however suggested that this procedure is a valid and reliable measure of infant feeding habits [46] and Natland et al. [47] recently confirmed in a great cohort analysis that maternal recall of breastfeeding duration was fairly accurate 20 years after delivery, meaning that our recalled duration of breastfeeding could be used in adolescents' population. In the HELENA study, breastfeeding recording was probably less exposed to recall bias than in previous studies conducted in the USA [48] because each European country participating in the HELENA study used a standardized health booklet that referred specifically to the type of infant feeding and its duration at all ages.

In conclusion this is the first European study to examine the relationship between breastfeeding and adolescents' body composition. The linkage study did not reveal a significant effect of breastfeeding on several variables reflecting body composition in the whole population. However a non-significant trend toward a protective effect of breastfeeding was highlighted on highest percentiles of abdominal adiposity. This observation suggests that the effect of breastfeeding on abdominal adiposity should be investigated in populations of highrisk adolescents.

\section{Acknowledgements}

The HELENA Study was carried out with the financial support of the European Community Sixth RTD Framework Programme (Contract FOOD-CT-2005-007034). The content of this paper reflects only the authors' views, and the European Community is not liable for any use that may be made of the information contained therein. The researchers from the University of Zaragoza, Spain are complementary supported by FUNDACION MAPFRE (Spain).

We thanks the ethics committees of all participating countries and the children involved in the HELENA study: The Hellenic National Bioethics Commission, Athens; The Ethics Committee of Forschungsinstitut für Kinderernährung Dortmund; The Ethics Commitee of Gent University Hospital; The Comité de Protection des 
Rousseaux et al.: Breastfeeding Shows a Protective Trend toward Adolescents with Higher Abdominal Adiposity

Personnes Nord-Ouest IV Lille; The Regional Research Ethics Committee of the Medical Center of Pécs; The Comitato Etico Per Le Attivita' Biomediche, Università Degli Studi di Napoli Federico II, Rome; The Regionala Etikprövningsnämnden Stockholm; The Ethik-Kommission der Medizinischen Universität Wien und des Allgemeinen Krankenhauses der Stadt Wien AKH Vienna; The Comité Ético de Investigacion Clinica de Aragon (CEICA), Zaragoza.

RJ carried out data analyses and drafted the manuscript. DA carried out data analyses and contributed revising the article. TD contributed revising the article. MD participated in the design and carried out the study. SJ carried out data analyses. AEG participated in the design and carried out the study and contributed revising the article. DHS participated in the design and carried out the study. DS participated in the design and carried out the study. MY participated in the design and carried out the study and contributed revising the article. PR participated in the design and carried out the study and contributed revising the article. SM participated in the design and carried out the study. MLA participated in the design and carried out the study and contributed revising the article. GF participated in the design and carried out the study and contributed drafting the article. All authors read and approved the final manuscript.

\section{Disclosure Statement}

Frédéric Gottrand has received consulting fees from Numico Clinical Nutrition, lecture fees from SMS and grant support from Danone Research. The remaining authors state no conflict of interest.

\section{References}

1 World Health Organization: Infant and Young Child feeding: Model Chapter for Textbooks for Medical Students and Allied Health Professionals. Geneva, World Health Organization, 2009.

2 Horta BL, Bahl R, Martines JC, Victora CG: Evidence of the Long-Term Effects of Breastfeeding: Systematic Reviews and Meta-Analysis. Geneva, World Health Organization Publication, 2007, pp 25-33.

-3 Cope MB, Allison DB: Critical review of the World Health Organization's (WHO) 2007 report on 'evidence of the long-term effects of breastfeeding: systematic reviews and meta-analysis' with respect to obesity. Obes Rev 2008;9:594-605.

4 Agostoni C, Braegger C, Decsi T, Kolacek S, Koletzko B, Michaelsen KF, Mihatsch W, Moreno LA, Puntis J, Shamir R, Szajewska H, Turck D, van Goudoever J: Breast-feeding: a commentary by the ESPGHAN committee on nutrition. J Pediatr Gastroenterol Nutr 2009;49:112-125.

5 Marmot MG, Page CM, Atkins E, Douglas JW: Effect of breast-feeding on plasma cholesterol and weight in young adults. J Epidemiol Community Health 1980;34:164-167.

6 Arenz S, Ruckerl R, Koletzko B, von Kries R: Breast-feeding and childhood obesity - a systematic review. Int J Obes Relat Metab Disord 2004;28:1247-1256.

7 Owen CG, Martin RM, Whincup PH, Davey-Smith G, Gillman MW, Cook DG: The effect of breastfeeding on mean body mass index throughout life: a quantitative review of published and unpublished observational evidence. Am J Clin Nutr 2005;82:1298-1307.

8 Harder T, Bergmann R, Kallischnigg G, Plagemann A: Duration of breastfeeding and risk of overweight: a metaanalysis. Am J Epidemiol 2005;162:397-403.

-9 Gale C, Logan KM, Santhakumaran S, Parkinson JR, Hyde MJ, Modi N: Effect of breastfeeding compared with formula feeding on infant body composition: a systematic review and meta-analysis. Am J Clin Nutr 2012;95: 656-669.

10 Engeland A, Bjorge T, Tverdal A, Sogaard AJ: Obesity in adolescence and adulthood and the risk of adult mortality. Epidemiology 2004;15:79-85.

-11 Bhat DS, Yajnik CS, Sayyad MG, Raut KN, Lubree HG, Rege SS, Chougule SD, Shetty PS, Yudkin JS, Kurpad AV: Body fat measurement in Indian men: comparison of three methods based on a two-compartment model. Int J Obes (Lond) 2005;29:842-848.

12 Freedman DS, Sherry B: The validity of BMI as an indicator of body fatness and risk among children. Pediatrics 2009;124(suppl 1):S23-34.

13 Moreno LA, De Henauw S, Gonzalez-Gross M, Kersting M, Molnar D, Gottrand F, Barrios L, Sjostrom M, Manios Y, Gilbert CC, Leclercq C, Widhalm K, Kafatos A, Marcos A: Design and implementation of the Healthy Lifestyle in Europe by Nutrition in Adolescence Cross-Sectional Study. Int J Obes (Lond) 2008;32(suppl 5):S4-11.

14 Moreno LA, Gonzalez-Gross M, Kersting M, Molnar D, de Henauw S, Beghin L, Sjostrom M, Hagstromer M, Manios Y, Gilbert CC, Ortega FB, Dallongeville J, Arcella D, Warnberg J, Hallberg M, Fredriksson H, Maes L, Widhalm K, Kafatos AG, Marcos A: Assessing, understanding and modifying nutritional status, eating habits and physical activity in European adolescents: The HELENA (Healthy Lifestyle in Europe by Nutrition in Adolescence) study. Public Health Nutr 2008;11:288-299. 


\begin{tabular}{l|l}
\hline \multicolumn{2}{l}{ Obes Facts 2014;7:289-301 } \\
\hline DOI: $10.1159 / 000368583$ & $\begin{array}{l}\text { C 2014 S. Karger GmbH, Freiburg } \\
\text { www.karger.com/ofa }\end{array}$ \\
\hline
\end{tabular}

Rousseaux et al.: Breastfeeding Shows a Protective Trend toward Adolescents with Higher Abdominal Adiposity

15 Beghin L, Castera M, Manios Y, Gilbert CC, Kersting M, De Henauw S, Kafatos A, Gottrand F, Molnar D, Sjostrom M, Leclercq C, Widhalm K, Mesana MI, Moreno LA, Libersa C: Quality assurance of ethical issues and regulatory aspects relating to good clinical practices in the HELENA cross-sectional study. Int J Obes (Lond) 2008; 32(suppl 5):S12-18.

16 Lohman TG, Roche AF, Martorell R: Anthropometric Standardization Reference Manual. Champaign, Human Kinetics Books, 1988.

17 Tanner JM, Whitehouse RH: Clinical longitudinal standards for height, weight, height velocity, weight velocity, and stages of puberty. Arch Dis Child 1976;51:170-179.

-18 Currie C, Molcho M, Boyce W, Holstein B, Torsheim T, Richter M: Researching health inequalities in adolescents: the development of the Health Behaviour in School-Aged Children (HBSC) family affluence scale. Soc Sci Med 2008;66:1429-1436.

-19 Iliescu C, Beghin L, Maes L, De Bourdeaudhuij I, Libersa C, Vereecken C, Gonzalez-Gross M, Kersting M, Molnar D, Leclercq C, Sjostrom M, Manios Y, Wildhalm K, Kafatos A, Moreno LA, Gottrand F: Socioeconomic questionnaire and clinical assessment in the HELENA cross-sectional study: methodology. Int J Obes (Lond) 2008; 32(suppl 5):S19-25.

20 Ortega FB, Artero EG, Ruiz JR, Espana-Romero V, Jimenez-Pavon D, Vicente-Rodriguez G, Moreno LA, Manios Y, Beghin L, Ottevaere C, Ciarapica D, Sarri K, Dietrich S, Blair SN, Kersting M, Molnar D, Gonzalez-Gross M, Gutierrez A, Sjostrom M, Castillo MJ: Physical fitness levels among European adolescents: the HELENA study. Br J Sports Med 2011;45:20-29.

21 Vereecken CA, Covents M, Matthys C, Maes L: Young adolescents' nutrition assessment on computer (YANA-C). Eur J Clin Nutr 2005;59:658-667.

-22 Vereecken CA, Covents M, Sichert-Hellert W, Alvira JM, Le Donne C, De Henauw S, De Vriendt T, Phillipp MK, Beghin L, Manios Y, Hallstrom L, Poortvliet E, Matthys C, Plada M, Nagy E, Moreno LA: Development and evaluation of a self-administered computerized 24-h dietary recall method for adolescents in Europe. Int J Obes (Lond) 2008;32(suppl 5):S26-34.

23 Dehne LI, Klemm C, Henseler G, Hermann-Kunz E: The German Food Code and Nutrient Data Base (BLS II.2). Eur J Epidemiol 1999;15:355-359.

24 Elliott SA, Davies PS, Nambiar S, Truby H, Abbott RA: A comparison of two screening methods to determine the validity of 24-h food and drink records in children and adolescents. Eur J Clin Nutr 2011;65:1314-1320.

-25 Nagy E, Vicente-Rodriguez G, Manios Y, Beghin L, Iliescu C, Censi L, Dietrich S, Ortega FB, De Vriendt T, Plada M, Moreno LA, Molnar D: Harmonization process and reliability assessment of anthropometric measurements in a multicenter study in adolescents. Int J Obes (Lond) 2008;32(suppl 5):S58-65.

-26 Ortega FB, Artero EG, Ruiz JR, Vicente-Rodriguez G, Bergman P, Hagstromer M, Ottevaere C, Nagy E, Konsta O, Rey-Lopez JP, Polito A, Dietrich S, Plada M, Beghin L, Manios Y, Sjostrom M, Castillo MJ: Reliability of healthrelated physical fitness tests in European adolescents. The HELENA study. Int J Obes (Lond) 2008;32(suppl 5):S49-57.

27 Cole TJ, Freeman JV, Preece MA: Body mass index reference curves for the UK, 1990. Arch Dis Child 1995;73: 25-29.

28 Ketel IJ, Volman MN, Seidell JC, Stehouwer CD, Twisk JW, Lambalk CB: Superiority of skinfold measurements and waist over waist-to-hip ratio for determination of body fat distribution in a population-based cohort of caucasian Dutch adults. Eur J Endocrinol 2007;156:655-661.

29 Brambilla P, Bedogni G, Moreno LA, Goran MI, Gutin B, Fox KR, Peters DM, Barbeau P, De Simone M, Pietrobelli A: Crossvalidation of anthropometry against magnetic resonance imaging for the assessment of visceral and subcutaneous adipose tissue in children. Int J Obes (Lond) 2006;30:23-30.

-30 Nambiar S, Truby H, Abbott RA, Davies PS: Validating the waist-height ratio and developing centiles for use amongst children and adolescents. Acta Paediatr 2009;98:148-152.

-31 Mokha JS, Srinivasan SS, Dasmahapatra P, Fernandez C, Chen W, Xu J, Berenson GS: Utility of waist-to-height ratio in assessing the status of central obesity and related cardiometabolic risk profile among normal weight and overweight/obese children: the Bogalusa Heart Study. BMC Pediatr 2010;10:73.

-32 D'Agostino RB Jr: Propensity score methods for bias reduction in the comparison of a treatment to a nonrandomized control group. Stat Med 1998;17:2265-2281.

33 Rehkopf DH: Quantile regression for hypothesis testing and hypothesis screening at the dawn of big data. Epidemiology 2012;23:665-667.

-34 Marques MD, Santos RD, Parga JR, Rocha-Filho JA, Quaglia LA, Miname MH, Avila LF: Relation between visceral fat and coronary artery disease evaluated by multidetector computed tomography. Atherosclerosis 2010;209: 481-486.

35 Novotny R, Daida YG, Grove JS, Acharya S, Vogt TM: Formula feeding in infancy is associated with adolescent body fat and earlier menarche. Cell Mol Biol (Noisy-le-grand) 2003;49:1289-1293.

-36 Victora CG, Barros F, Lima RC, Horta BL, Wells J: Anthropometry and body composition of 18 year old men according to duration of breast feeding: birth cohort study from Brazil. BMJ 2003;327:901.

-37 Grjibovski AM, Ehrenblad B, Yngve A: Infant feeding in Sweden: socio-demographic determinants and associations with adiposity in childhood and adolescence. Int Breastfeed J 2008;3:23.

-38 Holmes VA, Cardwell C, McKinley MC, Young IS, Murray LJ, Boreham CA, Woodside JV: Association between breast-feeding and anthropometry and CVD risk factor status in adolescence and young adulthood: the Young Hearts Project, Northern Ireland. Public Health Nutr 2009:1-8. 
Rousseaux et al:: Breastfeeding Shows a Protective Trend toward Adolescents with Higher Abdominal Adiposity

-39 Yin J, Quinn S, Dwyer T, Ponsonby AL, Jones G: Maternal diet, breastfeeding and adolescent body composition: a 16-year prospective study. Eur J Clin Nutr 2012;66:1329-1334.

-40 West SG, Duan N, Pequegnat W, Gaist P, Des Jarlais DC, Holtgrave D, Szapocznik J, Fishbein M, Rapkin B, Clatts M, Mullen PD: Alternatives to the randomized controlled trial. Am J Public Health 2008;98:1359-1366.

-41 Socha P, Grote V, Gruszfeld D, Janas R, Demmelmair H, Closa-Monasterolo R, Subias JE, Scaglioni S, Verduci E, Dain E, Langhendries JP, Perrin E, Koletzko B, European Childhood Obesity Trial Study Group: Milk protein intake, the metabolic-endocrine response, and growth in infancy: data from a randomized clinical trial. Am J Clin Nutr 2011;94(6 suppl):1776S-1784S.

-42 Weber M, Grote V, Closa-Monasterolo R, Escribano J, Langhendries JP, Dain E, Giovannini M, Verduci E, Gruszfeld D, Socha P, Koletzko B, for The European Childhood Obesity Trial Study Group: Lower protein content in infant formula reduces BMI and obesity risk at school age: follow-up of a randomized trial. Am J Clin Nutr 2014;99:1041-1045.

43 Beyerlein A, Toschke AM, von Kries R: Risk factors for childhood overweight: shift of the mean body mass index and shift of the upper percentiles: results from a cross-sectional study. Int J Obes (Lond) 2010;34:642648.

44 Ashwell M, Gunn P, Gibson S: Waist-to-height ratio is a better screening tool than waist circumference and BMI for adult cardiometabolic risk factors: systematic review and meta-analysis. Obes Rev 2012;13:275-286.

-45 Carmienke S, Freitag MH, Pischon T, Schlattmann P, Fankhaenel T, Goebel H, Gensichen J: General and abdominal obesity parameters and their combination in relation to mortality: a systematic review and metaregression analysis. Eur J Clin Nutr 2013;67:573-585.

46 Li R, Scanlon KS, Serdula MK: The validity and reliability of maternal recall of breastfeeding practice. Nutr Rev 2005;63:103-110.

47 Natland ST, Andersen LF, Nilsen TI, Forsmo S, Jacobsen GW: Maternal recall of breastfeeding duration twenty years after delivery. BMC Med Res Methodol 2012;12:179.

48 Gillespie B, d'Arcy H, Schwartz K, Bobo JK, Foxman B: Recall of age of weaning and other breastfeeding variables. Int Breastfeed J 2006;1:4. 